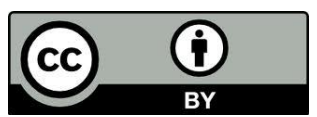

\title{
Marcos metodológicos e epistemológicos nos caminhos da Teologia feminista e da justiça de gênero
}

\author{
Methodological and epistemological frameworks in the paths of feminist theology \\ and gender justice
}

RESUMO: Este texto pretende discutir alguns pressupostos metodológicos e epistemológicos da Teologia Feminista em diálogo com a justiça de gênero, para em seguida levantar algumas suspeitas no campo da interpretação ou hermenêutica bíblica. Para entrar nas reflexões hermenêuticas, proponho traçar primeiro um caminho que coloca a reflexão teológica feminista no âmbito público e político. Neste caminho público, algumas balizas epistemológicas são as interseções com os direitos humanos, que tratam do empoderamento das mulheres, bem como com construções de políticas de justiça de gênero.

Palavras chave: teologia feminista, justiça de gênero, metodologia feminista

ABSTRACT: This text presents a reflection on some methodological and epistemological assumptions of the feminist theology in dialogue with gender justice; following some suspicions in the field of biblical interpretation. To enter in hermeneutic reflections, my proposal is first to trace a path that develops the feminist theological reflection in the public and political arena. In this public way, some epistemological markers are placed in interaction with human rights, with the movement of empowering women and building gender justice policies.

Keywords: Feminist Theology, gender justice, feminist methodology 
Este texto trata da Teologia Feminista em interação com instrumentais de análise crítica de gênero. As categorias de gênero fazem parte de um conjunto de instrumentais de análise no fazer teológico. Contudo, não podemos pensar que a teoria de gênero sozinha, seja capaz de problematizar em sua amplitude, as questões que buscam desvelar a participação e o protagonismo das mulheres nos diferentes espaços sociais, na teologia, na religião e nas Igrejas com seus diversos ministérios.

É preciso, igualmente, alertar para não cair nos artifícios usados em algumas instâncias, onde a palavra gênero tem sido usada no lugar de mulher ou do feminismo para suavizar o debate, para diluir a força política e transformadora do feminismo e dos movimentos de mulheres. Na tentativa de evitar o termo feminismo, prefere-se usar a categoria de gênero, enfraquecendo posturas políticas reivindicativas, promovendo ajustes e acomodações institucionais.

Ao usar as construções de gênero como instrumental de análise, é possível iniciar um processo de desconstrução dos valores e atitudes patriarcais. Joan Scott (1995) desenvolveu o cabedal teórico para usar o conceito gênero como um instrumental útil de análise histórica para questionar as expectativas e estereótipos culturais e sociais que definem o sujeito "mulher" ou "mulheres". Segundo Scott (1995), gênero constitui-se como um elemento constitutivo das relações sociais e é uma forma de dar significado às relações de poder. Com a categoria gênero pode-se questionar a noção fixa do sujeito mulher: "Esta não deveria ser pensada como um essência biológica pré-determinada, anterior à história, mas como uma identidade construída social e culturalmente no jogo das relações sociais e sexuais, pelas práticas disciplinadoras e pelos discursos/saberes instituintes" (RAGO, 1998).

Neste sentido, torna-se útil o uso do conceito de justiça de gênero, como impulsionador de construções de politicas de gênero, que se constituem em plataformas, estratégias e processos que instituições embarcam, no anseio de proporcionar marcos institucionais que dêem espaço a relações mais justas e equitativas. A justiça de gênero, como é compreendida neste artigo, tem sua base conceitual em concepções bíblicas e teológicas:

Justiça de gênero implica na proteção e promoção da dignidade das mulheres e dos homens que, sendo criados a imagem de Deus, são co-responsáveis cuidadores da criação. A justiça de gênero se expressa através da igualdade e 
através do equilíbrio nas relações poder entre homens e mulheres e, na eliminação de sistemas institucionais, culturais e interpessoais de privilegio e opressão que sustentam discriminação. (NEUENFELDT , 2013, p. 7).

O conceito de justiça de gênero é usado como um instrumento no processo de transversalizar e implementar a igualdade de gênero no contexto das organizações de fé e igrejas. Justiça de gênero é um conceito que tem seu fundamento na teologia, e desvela meandros importantes e desafiadores no contexto das igrejas, como por exemplo, o funcionamento e os mecanismos das relações de poder. No esforço de colocar em prática este conceito teológico, num espaço de comunhão inclusiva, o acesso ou não, o uso ou o mal-uso do poder nas estruturas hierárquicas e androcêntricas deve ser problematizado.

Neste artigo, o diálogo e o confronto abalizam o caminho das opções metodológicas e dos pressupostos epistemológicos: gênero e feminismo dialogam ampliando perguntas e suspeitas no campo da teologia e da religião.

\section{Deslocamentos teológicos necessários no caminho metodológico da Teologia Feminista e dos instrumentos da justiça de gênero}

Em primeiro lugar objetivo problematizar a discussão dos referenciais da teologia feminista, refletindo, por um lado, o papel desta na interação com os espaços públicos ou os lugares de efetivação das políticas públicas, e por outro, temas e reflexões que culturalmente são colocados no âmbito privado, como por exemplo a violência de gênero, questões ligadas a corporeidade, sexualidade, etc, e ali normatizados e naturalizados, e, portanto, não passíveis de questionamentos e desestabilizações.

Outro deslocamento deriva do fato da teologia feminista e das teorias de gênero situarem-se num lugar de crítica à cultura e à religião patriarcal, que servem de alicerce para uma sociedade que exclui e limita mulheres e alguns homens que não se encaixam nos padrões hegemônicos de masculinidade. Esses modelos hierárquicos de sociedade, que criam sujeitos subordinados, contribuem para o surgimento de movimentos de crítica e resistência, não só das mulheres, mas, de grupos que se encontram às margens do poder normativo. É interessante notar que há um deslocamento nas discussões sobre a constituição do sujeito e na contextualização das identidades que se articulam em 
espaços diferentes, e estão em constantes movimentos e intersecções (TROCH, 2007, p. 37-39).

A teologia feminista articula a produção de conhecimento em interface com distintas fontes do movimento feminista e sublinha que: "o feminismo propõe uma nova relação entre teoria e prática. Delineia-se um novo agente epistêmico, não isolado do mundo, mas inserido no coração dele, não isento e imparcial, mas subjetivo, afirmando a sua particularidade" (RAGO, 1998, p. 30).

\section{Do lugar da teologia feminista e da justiça de gênero no diálogo com os espaços públicos}

Esta interação com o espaço público suscita a pergunta pelo lugar e o sentido das contribuições teológico-feministas para a constituição de políticas públicas, especialmente, se considerada a prerrogativa da laicidade do Estado.

A pergunta é pelo lugar do pensamento religioso, articulado em concepções teológicas, como mantenedor, justificador ou desestabilizador das normas e valores de gênero, vigentes no contexto social. Tradicionalmente, a religião tem funcionado como freio para os movimentos que buscam seus avanços nas políticas de igualdade de direitos entre homens e mulheres, especialmente nas propostas relacionadas com os campos da sexualidade e da corporeidade. Contudo, há controvérsias e paradoxos em relação ao papel da religião no seio dos movimentos sociais. Há experiências positivas, que se apresentam como luzes capazes de iluminar o horizonte:

\footnotetext{
Organizações eclesiais, de fé podem desafiar preconceitos e dar apoio para a participação integral das mulheres na vida política, econômica e social ao refutar atitudes que perpetuam a desigualdade. Mulheres são na maioria das vezes, centrais na vida das organizações de fé; as mulheres possuem um enorme potencial de resolução de conflitos e construção da paz. Há numerosos exemplos inspiradores, incluindo a ganhadora do prêmio nobel da paz Leymah Gbowee, que juntou mulheres muçulmanas e cristãs num efetivo movimento de paz, na Libéria (NEW YORK, 12 February 2013).
}

Sistemas culturais de conhecimento, comportamentos, crenças, valores e símbolos aceitos e compartilhados por um determinado grupo de pessoas, não se constituem num esquema estático, mas dinâmico, cambiante e em movimento. Estas organizações culturais muitas vezes interconectadas com perspectivas de fé e de religião 
permeiam percepções e moldam comportamentos que normalmente representam exclusão para as mulheres. Historicamente, algumas instituições religiosas e de fé, como igrejas, criaram e perpetuaram narrativas de subserviência das mulheres através de seus ensinamentos e estruturas patriarcais, baseadas em valores e crenças culturais fixas, inamovíveis.

No entanto, os discursos religiosos e as práticas de fé podem igualmente jogar um papel importante na desconstrução de estereótipos de gênero, cooperando para redefinição de papéis e estruturas que dão espaço para a igualdade.

As reflexões da teologia feminista ou das interações entre justiça de gênero e religião têm demonstrado que há outras portas e caminhos possíveis de abertura. A religião pode então, por um lados ser considerada como lugar de contradições e resistências, por outro, para além de forças conservadoras pode significar espaço de mobilização e luta das mulheres. Contudo é preciso ter presente que: "grande parte da teoria feminista ainda duvida da capacidade de um movimento iniciado em uma igreja dominada por homens [que seja capaz] de emancipar mulheres" (DROGUS, 1997, p. 6).

Uma das perguntas que se coloca aqui é: porque trabalhar o aspecto religioso, misturado no bojo das reivindicações articuladas pelas mulheres, nos espaços das políticas públicas e nos movimentos sociais? É fundamental observar o lugar que a religião tem na vida das pessoas, especialmente nas lutas e mazelas cotidianas de mulheres. A religião continua exercendo um papel fundamental na formatação dos comportamentos individuais e sociais em relação ao feminino. Um papel, que na maioria das vezes, possui um caráter punitivo e restritivo, com poderes de controle e de limitações. Isso revela que a religião perpassa as subjetividades e continua moldando comportamentos, representando com frequência, interdições na vida de mulheres e homens.

A religião e seus textos sagrados atuam na produção e na reprodução de sistemas simbólicos que têm influência sobre as relações sociais de gênero, ou seja, na representação religiosa e social do masculino e do feminino tornando-se muitas vezes cúmplices da violência (NEUENFELDT, p. 2008, p. 7-12). Um dos problemas identificados na construção e na afirmação de políticas públicas e de superação da violência tem sido o papel fundamental que a religião, em especial a tradição cristã, continua tendo na formatação dos comportamentos individuais e sociais em relação ao 
feminino. A teologia cristã patriarcal - hegemônica nos espaços eclesiais do continente latino-americano - alimenta e justifica a lógica sacrificial que faz dos corpos das mulheres lugar de punição e castigo (GEBARA, 1997. p. 18-21).

Contudo e felizmente, a religião e a teologia não se restringem aos tapetes oficiais das igrejas, não se limitam aos cânones tradicionais já bem delimitados. As franjas de contradições escorrem por entre os dedos que querem segurar o poder de nomear e normatizar o saber religioso. Por isso, é importância partir das experiências das mulheres, como lugar teológico, como espaço que gera reflexões teológicas.

Neste diálogo do lugar público e constitutivo de cidadania da teologia feminista, a pergunta é: os elementos teológicos e religiosos contribuem nas discussões e nas proposições da esfera pública de serviços, favoráveis à defesa dos direitos das mulheres? Seriam estes elementos - altamente implicados no imaginário cultural, de fato considerados nos debates, por exemplo, a respeito de tema como violência doméstica, direitos sexuais e reprodutivos? A pergunta a ser debatida é em que medida a posição de vulnerabilidade das mulheres por causa das concepções religiosas afeta suas experiências e suas vivências cidadãs no campo do enfrentamento da violência, das experiências de sexualidade e na reivindicação dos direitos reprodutivos?

Um exemplo ajuda a entender o questionamento: o argumento de um homem violento, que afirma, com a Bíblia em mãos, que ali, neste texto sagrado encontra a base de seu comportamento, pois está escrito: a mulher deve ser submissa ao marido. Portanto, quando ele a repreende, a agressão é na verdade para que ela assuma o seu papel descrito na Bíblia: ser esposa, fiel e submissa. O discurso articulado deste homem, que pratica a violência, que até pode ser denunciado e estar em posição de sofrer juízo no espaço público destinado para tal, é de lançar mão de um argumento religioso, de um ensinamento bíblico-teológico, para justificar, embasar a sua prática violenta, dando-lhe até um aspecto de testemunho e de fidelidade evangélica. É aqui que se evidencia como a religião, a teologia ou o discurso religioso segue tendo valor e peso na estruturação social, familiar e consequentemente, nos assuntos que ali são tratados, como as relações conjugais, sexuais e afetivas.

Promover uma reflexão teológica a partir das experiências das mulheres, articulada com instrumentais feministas e das teorias de gênero, irá trazer novas abordagens e novas argumentações às temáticas implicadas em políticas públicas. 
Nos tempos em que se misturam as entre poderes políticos e religiosos de forma explícita nos espaços públicos brasileiros, o argumento religioso ou teológico em relação a muitos temas sociais e políticos, ou mesmo, outrora considerados privados, já é público. Para isso, pode se verificar os debates em torno à noção de família, sexualidade, aborto, entre outros. Por isso, o diálogo que a teologia feminista, deverá articular com os instrumentais da justiça de gênero e com os espaços de políticas públicas é fundamental. É preciso, contudo, entender que quando dizemos a palavra pública a partir da a teologia, não nos referimos a punição, culpabilização, acomodação, justificação de violências. Há outra palavra a serem ditas. Uma palavra que leve em conta a experiência, os corpos, a vida cotidiana das mulheres, como sujeitos éticos responsáveis de suas decisões.

A teologia feminista, com o apoio crítico dos instrumentais de gênero, é convocada a articular estas e outras palavras, de diálogo, de abertura, de reflexão, motivada e enriquecida a partir das experiências das próprias mulheres. É preciso ouvir de verdade o que as mulheres dizem quando falam de suas experiências de violência, de vivências de sexualidade, e não enquadradas nos moldes da oficialidade teológica. Quem sabe repetem, como uma ladainha as frases dos homens fazedores de religião, pretendendo moldar os corpos das mulheres. Mas, quem sabe balbuciam palavras outras, ainda mal-ditas, sus/surradas, que des-dizem, contradizem o discurso sempre tão tradicional, conhecido, de(s)corado.

É assim que um movimento público da teologia feminista pode ser percebido: ajudando a dizer, auxiliando a parir palavras, gestos, saberes que por sua vez ajudam para que as mulheres se ponham de pé, em dignidade e auto-estima e floresçam.

\section{No movimento dos círculos ou espirais hermenêuticos - a Bíblia em diálogo com a experiência das mulheres}

Partir da experiência das mulheres como critério de interpretação bíblica implica em se perguntar pelas vivências das mulheres em relação com a realidade política, social, econômica, religiosa, cultural e pessoal. É preciso tomando o devido cuidado metodológico para não isolar as mulheres da análise de sua realidade. As mulheres estão inseridas em grupos sociais e sua experiência deve ser interpretada a partir das relações que são estabelecidas entre os sujeitos. Por isso, partir das experiências das mulheres 
requer também uma pergunta pelas relações nas quais elas estão entrelaçadas, o que quer dizer que os homens estão incluídos nesta trama.

Aqui são necessárias perguntas que problematizem as situações concretas que as mulheres enfrentam em seu cotidiano e, especialmente, como estas situações são vivenciadas em seus corpos. O contexto econômico, com a realidade de empobrecimento e exclusão, que é o cotidiano de muitas mulheres deve ser analisado criticamente. As realidades diferenciadas pela idade, pela pertença a etnias específicas e grupos sociais devem ser observadas com atenção e problematizadas. Estas perguntas devem provocar e impulsionar a movimentos que levam as mulheres a reapropriar-se do poder de dizer a sua própria palavra. Implica num poder de nomear a sua vida em todas as dimensões possíveis: com seus cantos, suas danças, suas realidade corporais, seus lamentos e choros, seus silêncios, suas comidas, seus cheiros, suas alegrias, seus prazeres, seus saberes e sabores.

O movimento que parte da experiência, para logo fazer uma análise das estruturas e relações, para então adentrar no texto bíblico, para exercícios de leitura crítica, que vão desenvolver novas interpretações e novas construções teológicas é conhecido, como círculo hermenêutico (SEIBERT, 2010, p. 53-55).

Uma leitura feminista da Bíblia, que usa os instrumentais de justiça de gênero como aparato metodológico crítico, faz um movimento de dança espiral: tem como ponto de partida os corpos das mulheres, na diversidade da vida cotidiana, marcada pela cultura patriarcal e as relações que esta gera; atravessando os textos bíblicos e a tradição teológica com uma leitura crítica, gerando novas interpretações e novas mensagens bíblicas e teológicas (SEIBERT, 2010, p. 56). A imagem da dança abraça toda a dimensão corporal, dinâmica e de movimento que este exercício metodológico desenvolve. FIORENZA, 2001, p. 7-18). O exercício de leitura critica feminista não é isento de conflitos e rupturas, por isso, exercícios críticos que lançam olhares por detrás dos textos, perguntando pelos contextos e pelos arcabouços ideológicos que sustentam os interesses de dominação, e se inscrevem nos textos bíblicos, se fazem necessários. 


\section{Suspeita - um critério de análise dos textos bíblicos}

Ter a suspeita (FIORENZA, 2001, p. 175) como critério de análise implica em fazer perguntas críticas que vão abrindo os referenciais e as possibilidades de interpretação dos textos. Suspeitamos não da Bíblia em si, mas do processo de escritura dos textos, das opções político-religiosa-econômica que regiam aqueles que redigiram o texto. Suspeita-se das traduções usadas que privilegiam uma linguagem masculina. Suspeita-se da história da interpretação que imprimiu no texto uma versão androcêntrica e patriarcal. Adotar uma postura metodológica de suspeita é adotar a crítica, a pergunta, a não conformidade com o estabelecido como critério de análise.

A configuração das redes de organização social deve ser analisada criticamente a partir de perguntas que evidenciam o lugar social das mulheres, bem como as expectativas de gênero que são postas a homens e mulheres.

Suspeitar da formatação final do texto bíblico, de sua redação, linguagem, experiência relatada e assumida como única, da tradição interpretativa, da pretensa universalidade implícita ou explícita é uma maneira de buscar caminhos outros, experiências outras e realidades outras que estão presentes nos textos. Presença que está às vezes explícita, mas que não foi abordada ainda ou outras vezes está nas entrelinhas, no não dito, nos silêncios do texto.

\section{Desconstrução: um processo que ajuda a entender o contexto do texto} bíblico.

Desconstrução não é o mesmo que destruição. Desconstruir algo, requer um exercício cuidadoso, atento, analítico de um processo de estudo de textos e contextos bíblicos. O processo de desconstrução do texto bíblico busca estabelecer movimentos que questionem a normativa imposta pelo sistema patriarcal, androcêntrico e sexista de que o modelo para interpretar e produzir conhecimento é o homem. Nesse processo, é necessário analisar a dinâmica de poderes presentes no texto, ou seja, como homens e mulheres são construídos cultural e socialmente e quais os mecanismos que usam para o acesso e exercício do poder, os quais podem ser percebidos no texto ou nas suas entrelinhas.

A desconstrução, como instrumental metodológico permite que se achegue o mais próximo possível das realidades que originaram o texto bíblico. Permite que 
conheçamos o contexto em que o texto surgiu, quais as experiências de vida que originaram o texto e como este se articula com as realidades pessoas e comunitárias que aparecem no contexto. Aqui é fundamental perguntar também pelos silêncios do texto, ou seja, devemos perguntar de que o texto fala, mas igualmente dar valor aos assuntos que o texto cala. Porque determinados assuntos não são tratados no texto, quais os silêncios do texto ou quais as outras linguagens - corporais, simbólicas, metafóricas que o texto evidencia. É fundamental perguntar se o texto é uma construção normativa no sentido de querer estabelecer uma regra ou um comportamento a um determinado grupo social, como as mulheres, ou seja, se o texto quer prescrever uma norma ou um ideal, ou se está descrevendo uma situação.

\section{Abrindo horizontes para seguir caminhando}

Há um dito conhecido sobre para que serve o horizonte, que é pra seguir caminhando. O horizonte não aponta o inalcançável, mas motiva o movimento, a dança e o pé na estrada, à caminho. Assim também no exercício crítico de leituras bíblicas e no movimento de empoderamento de mulheres. A caminhada não começou ontem, mas há muito tempo. Memória de marcos importantes deste processo ajudam criar motivações de seguir caminhando.

Já em 1895, uma sufragista norte-americana teve a iniciativa de propor uma Bíblia das Mulheres (CADY, 1974). Ela reuniu um grupo de mulheres, militantes dos direitos das mulheres, e numa dinâmica de recortar os textos bíblicos que falam sobre mulheres, e, costurá-los, compilando um novo compêndio de textos sagrados, edita a Bíblia das Mulheres. No capítulo 3, do livro de Gênesis, que trata sobre a conversa da mulher com a serpente ela dispara: Vai ver que a mulher estava cansada, aborrecida de ficar colhendo flores e passeando pelo jardim, e mais enjoada ainda com as conversas que mantinha com Adão, e achou o diálogo com a serpente muito mais desafiador e construtivo.

Há que suspeitar desta transgressão: a mulher vai em busca de conhecimento. Ela rompe uma fronteira que a mantém alienada. Ela não se contenta com a regra, quer saber as implicações. A consequência é que elas se tornam adultos ou autônomos, de certa forma. Não precisam mais da tutela da divindade. A relação com a Divindade 
também muda, numa interação de crescimento e liberdade responsável. São sujeitos de suas decisões. Assumem a responsabilidade de suas decisões.

A ideia de que a tradição judaico-cristã prega a submissão das mulheres é no mínimo uma leitura parcial. Isso de que as mulheres se calem, de que as mulheres têm atributos que lhe qualificam como inferiores, fracas ou impuras, é uma possibilidade de leitura. Mas, não é a única e quem sabe nem é a hegemônica em alguns setores. As correntes ortodoxas e tradicionais, ou melhor, os fundamentalismos religiosos devem ser evidenciados. O movimento feminista já tem trabalhado há tempos sobre como as visões fundamentalistas negam a diversidade, se apoiam em ações belicosas e justificam a violência.

Reler a tradição teológica cristã e os textos bíblicos desde uma perspectiva feminista-libertadora implica buscar as ações protagônicas das mulheres na história. Alude primeiro que é preciso desarraigar a tradição patriarcal e excludente que legitima a submissão e subordinação das mulheres. Reler a história é mais do incluir as mulheres, mas é desconstruir paradigmas e modelos. É ler nas entrelinhas da história patriarcal como as mulheres desafiam o poder. É este o papel público e político a ser desenvolvido pela teologia feminista e pelos processos de contruções coletivas de políticas de justiça de gênero.

\section{Referências}

CADY STANTON, Elizabeth (ed.). The woman's Bible. Seattle: Coalition Task Force on women and religion, 1974.

DROGUS, Carol. Women, Religion, and Social Change in Brazil's Popular Church. Notre Dame, Indiana: University of Notre Dame Press, 1997.

FIORENZA, Elizabeth Schussler. Wisdom Ways. Feminist Biblical Interpretation, New York, Orbis, Maryknoll, 2001.

GEBARA, Ivone. Teologia Ecofeminista. Ensaio para repensar o conhecimento e a religião. São Paulo, Olho d'Agua, 1997.

NEUENFELDT, Elaine (ed.) Gender Justice Policy. Geneva: The Lutheran World Federation, 2013. Disponível em: http://www.lutheranworld.org/content/resource-lwfgender-justice-policy. Acesso em: 20.01.2014.

NEUENFELDT, Elaine. Abrindo as janelas. Olhares da Teologia Feminista, Gênero e Religião sobre Epistemologia, Violência e Sexualidade. In. NEUENFELDT, E. 
Bergesh, K. Parlow, M. Epistemologia, Violência, Sexualidade. Olhares do II Congresso Latino-Americano de Gênero e Religião. São Leopoldo, 2008.

NEW YORK, 12 February 2013. Secretary-General's message to Symposium on "The Role of Interfaith Dialogue in Peacebuilding and Women Empowerment" [delivered by Mrs. Lakshmi Puri, Assistant Secretary-General for Intergovernmental Support and Strategic Partnerships, UN Women]. Disponível em: http://www.un.org/sg/statements/index.asp?nid=6598. Acesso em: 20.12.2013.

RAGO, Margareth. Epistemologia feminista, gênero e história. Publicado em: Pedro, Joana; Grossi, Miriam (Orgs.). Masculino, Feminino, Plural. Florianópolis: Ed. Mulheres, $1998 . \quad$ Disponível em: http://www.moodle.ufba.br/file.php/12635/Carla_Akotirene/Epistemologia_Feminista.p df. Acesso 20.01.2014

ROSADO, Maria José, O impacto do feminismo sobre os estudos das religiões. Cadernos pagu (16) 2001, pp.79-96.

SCOTT, J. Gênero: uma categoria útil de análise histórica. Revista Educação \& Realidade. Porto Alegre: v. 2, n. 20, p.71-99, Jul/Dez, 1995. Disponível em: http://www.fazendogenero.ufsc.br/7/artigos/G/Graziela_Frainer_Knoll_02.pdf. Acesso em: 15.012.2013.

SEIBERT, Ute. Espacios abiertos: caminos de la teologia feminista. Editorial Forja: Santiago de Chile, 2010.

TROCH, Lieve. Exercícios em maravilhar-se. Fronteiras e transgressões de fronteiras na teologia feminista. In. TROCH, Lieve (Org.). Passos com paixão. Uma teologia do diaa-dia. São Paulo: Nhanditu, 2007.

Anna Maria Pezzella.

Recebido: 10/09/2013

Received: 09/10/2013

Aprovado: $19 / 12 / 2013$

Approved: 12/19/2013 